\title{
Extrinsic And Intrinsic Motivators Of Customer Participation In Compliance Dependent Services
}

Tiffany Barnett White, University of Illinois at Urbana Champaign Gail Ayala Taylor, Dartmouth College

Stephanie Dellande, (E-mail: dellande@chapman.edu), Chapman University

\begin{abstract}
Research on customer participation has focused primarily on the customer's participatory role in service creation during the face-to-face service exchange (Bateson 1989; Bowen 1986; Chase 1978; Kelley, Donnelly, and Skinner 1990; Lovelock and Young 1979; and Mills, Chase, and Margulies 1983) however customer involvement often extends beyond the face-to-face exchange. This is especially the case with compliance dependent services (CDS). CDS are services that require customer participation with his or her service delivery role while within the service organization and once away from the service facility to ensure goal attainment and customer satisfaction. Examples of CDS include dental care, weight loss programs, preventive auto maintenance, education, exercise programs, health care programs (diabetes, hypertension), prenatal care, long-term financial planning, debt management programs, and smoking cessation programs.
\end{abstract}

In an early CDS study, Dellande (1999) found motivation to be the most important customer attribute in gaining customer compliance. In this research we further our understanding of the role of motivation by studying the impact of persuasive provider communication, an extrinsic customer motivator, on intrinsic customer compliance motivation. One important characteristic of persuasive messages that influences their effectiveness is how they are framed. Among other factors, effective persuasive messages require comprehension and retention, yielding and behavior in accordance with the message content (McGuire 1966). Specifically, existing research suggests that behavior is affected by the extent to which messages emphasize the potentially negative consequences of failing to engage in a given behavior relative to a message in which the possible beneficial (i.e., positive) consequences of engaging in that action are emphasized (Roberson and Rogers 1988, Tykocinski et. al, 1994). We explore this distinction in the dental compliance service context. We specifically examine how the manner in which written compliance-related communications are framed influences consumers' intended compliance behaviors.

\section{Theoretical Framework}

Theories regarding the impact of message framing on persuasion are equivocal (Rothman \& Salovey 1997). For example, both prospect theory (Kahneman and Tversky 1982) and the negativity bias theory (Kanouse \& Hanson 1972) would suggest that potential losses are more salient and weighted more heavily than potential gains, leading to greater compliance when the negative consequences of failing to behave in a recommended way are emphasized relative to when positive consequences of the same behavior are emphasized. Conversely, other research suggests that, under certain conditions, for example when individuals hold either ambiguous or moderate attitudes toward the target behavior, positively framed messages can be more effective in persuasion than negatively framed messages (van Assema et. al, 2001, Tykocinski et. al, 1994). 
In this study we test two mechanisms that may explain the differential impact of positively versus negatively framed messages on persuasiveness in general and compliance in particular. One mechanism relates to the consumer's self-regulatory focus. Self-regulatory theory captures individuals' intrinsic motivations for behavior and conceptually differentiates between processing styles associated with promotion (i.e., gain seeking) and prevention (i.e., loss avoiding) goals (Higgins 1999). Accordingly, we will explore the moderating role of selfregulatory focus on consumers' reception to positively and negatively framed messages.

We also examine the impact of another variable that might affect the relationship between message frame and compliance, namely the type of compliance in question. Compliance has typically been conceptualized by the degree to which the compliant behavior occurs (e.g., the extent to which a weight loss patient follows a physician's suggestion to eat healthier foods or to begin an exercise regiment). However, in this research we attempt to broaden this one-dimensional conceptualization of compliance in a manner that further clarifies its complexity. Specifically, we explore the notion that compliance also varies by the extent to which the compliance behavior requires an action or inaction on the consumer's part (i.e., relative to the consumer's "status quo" behavior). For example, the goal of attaining healthy teeth and gums may be reached both by flossing regularly (action) as well as by eliminating sugary or sticky foods from one's diet (inaction). Drawing from regret theory research, we test the prediction that the effects of message framing on consumers' compliance behaviors may also be affected by the extent to which actual compliance requires actions or inactions.

Taken together, the discussion above motivates the following hypotheses:

H1: Individuals with a promotion focus will be more likely to comply with positively framed messages (relative to those with a prevention focus); however, individuals with a prevention focus will be more likely to comply with negatively framed messages.

H2: Individuals exposed to negatively framed messages will be more likely to engage "inaction-based" compliance (relative to those exposed to positively framed messages); however, individuals exposed to negatively framed messages will be less likely to engage in "action-based" compliance.

\section{Summary of Method and Findings}

The hypotheses above were tested in an experimental setting that employed a 2 (message frame: positive/negative) X 2 (self regulatory focus: promotion/prevention) X 2 (compliance type: action/inaction) completely between subjects design. 175 subjects were randomly assigned to one of eight treatment conditions. All subjects read a standard introductory paragraph that described a situation in which Sharon, a recent college graduate, moved to a new location and received a referral for a new dentist. Based upon treatment condition the subjects then read a paragraph describing Sharon's visit with the dentist and her prior status quo dental behavior. Sharon's goal for visiting the dentist (which varied by whether it was promotion or prevention focused) was described in this context. The subjects then read an excerpt from a pamphlet (the content of which was either framed negatively or positively) supplied by the dentist that suggested a recommended compliance behavior (that required either an action or an inaction on the Sharon's part). After reading the scenario, respondents answered a set of questions designed to measure perceived compliance likelihood as well as other relevant manipulation check and covariate assessments.

In general, the results of the study support our predictions. We find no significant main effects in the model, however the results show that the effects of message frame on compliance likelihood are indeed moderated by self-regulatory focus and compliance type. Specifically, controlling for compliance task difficulty, respondents' prior dental behaviors, and other relevant measures, we find both a significant self-regulatory focus by message frame interaction $(\mathrm{F}(1,174)=5.56 ; \mathrm{p}<.05)$ and a significant compliance type by message frame interaction $(\mathrm{F}(1,174)=4.66 ; \mathrm{p}<.05)$. The simple means for the interaction effects are as expected. 


\section{Conclusions}

CDS are long term in nature requiring the customer to consistently perform over the duration of the service delivery period (Dellande and Gilly 1998). The customer is generally required to make an investment in education about his or her role and is often required to make lifestyle changes (that may or may not be welcomed). Gaining compliance is critical to realizing the desired outcome and yet often difficult to achieve. Noncompliance, however, can often have adverse consequences, e.g., poor health, financial hardship, and even death. Thus examining CDS and understanding the role of motivation in gaining customer compliance is extremely important to the individual, the service firm, and society at large.

The framework developed specifically examines the role of provider communications in general, and message frame in particular, in influencing customer compliance. The results of our study provide support for the notion that the manner in which a message is framed influences compliance behaviors, but reveals that these effects are moderated by the extent to which the consumer is intrinsically or extrinsically motivated to pursue positive outcomes (i.e., is promotion focused) or to avoid negative outcomes (i.e., is prevention focused). While this motivational distinction has been studied as an individual trait in the social science literature, our research builds upon the growing body of work that demonstrates that these motivational states can be situationally manipulated as well. Our results suggest that when consumers become goal seeking (i.e., are promotion focused), they respond more positively to positively framed messages, whereas the opposite is true for those who are more prevention focused.

A second component and contribution of the developed framework involves our introduction and preliminary investigation of the theoretical distinction between types of compliance behaviors. Our results show that the effects of message frame are also moderated by the extent to which the compliant behavior necessary to achieve a given outcome requires an action or an inaction on the consumer's part, relative to his/her "status quo" or "normal" behaviors (or lack thereof). Respondents reported greater compliance likelihood when exposed to negative messages about inaction-based (relative to action-based) compliance types, whereas the opposite was true for those exposed to positively framed messages. The results also intimate that, as theorized, the mechanism underlying this effect is greater anticipated regret for actions than inactions among those in the negative frame conditions.

While the results of this study are promising, there are opportunities for improvement. For example, in this study we examine the phenomena at hand in an experimental setting using hypothetical scenarios. While this approach was useful in providing preliminary support for the developed framework, future studies are aimed at testing the compliance phenomenon in a more externally valid context. For example, future research will test actual compliance (rather than compliance likelihood). We will also attempt to validate the study findings in additional compliance dependent service contexts.

\section{References}

1. Bateson, John E. G. 1977. "Do We Need Service Marketing?", in Marketing Consumer Service: New Insights, Cambridge, MA: Marketing Institute, Report \# 77-115.

2. _ 1989. Managing Services Marketing, Chicago: The Dryden Press.

3. Bowen, David. 1986. "Managing Customers as Human Resources in Service Organizations", Human Resources Management 25: 371-383.

4. Chase, Richard B. 1978. "Where Does the Customer Fit in a Service Operation?", Harvard Business Review 56 (November-December): 137-142.

5. Dellande, Stephanie. 1999. "Gaining Customer Compliance in Services", Dissertation. University of California at Irvine.

6. _ and Mary Gilly. 1998. "Gaining Customer Compliance in Services", Advances in Services Marketing and Management 7: 265-292. 
7. Higgins, E. Tory. "Promotion and prevention as a motivational duality: Implications for evaluative processes", in Chaiken, Shelly (Ed); Trope, Yaacov (Ed). (1999). Dual-process theories in social psychology. (pp. 503-525).

8. Kahneman, Daniel; Tversky, Amos. "Variants of uncertainty", Cognition. Vol 11(2) Mar 1982, 143-157.

9. Kelley, Scott, James H. Donnelly Jr., and Steven Skinner. 1990. "Customer Participation in Service Production and Delivery", Journal of Retailing 66: 315-335.

10. Lovelock, Christopher and Robert F. Young. 1979. "Look to Consumers to Increase Productivity", Harvard Business Review 57 (May-June): 168-178.

11. McGuire, William J. "Attitudes and opinions", Annual Review of Psychology. 17 1966, 475-514. Annual Reviews, US

12. Mills, Peter K, Richard B. Chase, and Newton Margulies. 1983. "Motivating the Client/Employee System as a Service Production Strategy", Academy of Management Review 8: 301-310.

13. Rothman, Alexander J; Salovey, Peter. "Shaping perceptions to motivate healthy behavior: The role of message framing", Psychological Bulletin. Vol 121(1) Jan 1997, 3-19.

14. Tykocinski, Orit; Higgins, E. Tory; Chaiken, Shelly. "Message framing, self-discrepancies, and yielding to persuasive messages: The motivational significance of psychological situations", Personality \& Social Psychology Bulletin. Vol 20(1) Feb 1994, 107-115. Sage Publications, US

15. van Assema, Patricia; Martens, M; Ruiter, A. C; Brug, J. "Framing of nutrition education messages in persuading consumers of the advantages of a healthy diet", Journal of Human Nutrition \& Dietetics. Vol 14(6) Dec 2001, 435-442.

Notes 